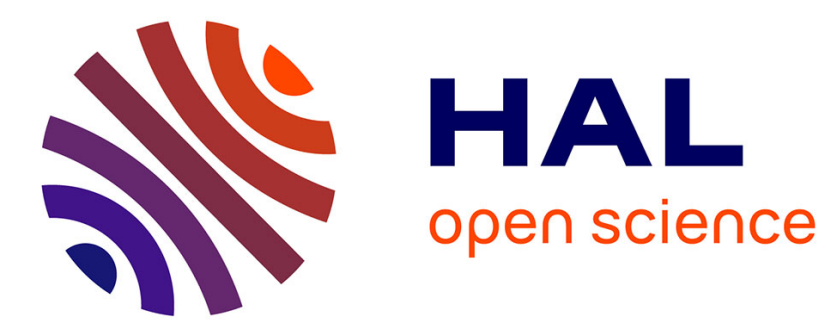

\title{
Special Digital Monies: The Design of Alipay and WeChat Wallet for Mobile Payment Practices in China
} Yong Ming Kow, Xinning Gui, Waikuen Cheng

\section{To cite this version:}

Yong Ming Kow, Xinning Gui, Waikuen Cheng. Special Digital Monies: The Design of Alipay and WeChat Wallet for Mobile Payment Practices in China. 16th IFIP Conference on Human-Computer Interaction (INTERACT), Sep 2017, Bombay, India. pp.136-155, 10.1007/978-3-319-68059-0_9 . hal-01679828

\section{HAL Id: hal-01679828 \\ https://hal.inria.fr/hal-01679828}

Submitted on 10 Jan 2018

HAL is a multi-disciplinary open access archive for the deposit and dissemination of scientific research documents, whether they are published or not. The documents may come from teaching and research institutions in France or abroad, or from public or private research centers.
L'archive ouverte pluridisciplinaire HAL, est destinée au dépôt et à la diffusion de documents scientifiques de niveau recherche, publiés ou non, émanant des établissements d'enseignement et de recherche français ou étrangers, des laboratoires publics ou privés. 


\title{
Special Digital Monies: The Design of Alipay and WeChat Wallet for Mobile Payment Practices in China
}

\author{
Yong Ming Kow ${ }^{1}$, Xinning Gui ${ }^{2}$, Waikuen Cheng ${ }^{1}$ \\ ${ }^{1}$ School of Creative Media \\ City University of Hong Kong \\ Kowloon Tong, Hong Kong \\ yongmkow@cityu.edu.hk, wikncheng@gmail.com \\ ${ }^{2}$ Department of Informatics \\ University of California, Irvine \\ Irvine, CA 92697-3440, USA \\ guix@uci.edu
}

\begin{abstract}
While research studies of digital and mobile payment systems in HCI have pointed out design opportunities situated within informal and nuanced mobile contexts, we have not yet understood how we can design digital monies to allow users to use monies more easily in these contexts. In this study, we examined the design of Alipay and WeChat Wallet, two successful mobile payment apps in China, which have been used by Chinese users for purposes such as playing, gifting, and ceremonial practices. Through semi-structured interviews with 24 Chinese users and grounded theory coding, we identified five contexts in which the flexibility and extensive functions of these payment apps have allowed these users to adaptively use digital monies in highly flexible ways. Finally, our analysis arrived at our conceptual frame-special digital monies - to highlight how digital monies, by allowing users to alter and define their transactional rules and pathways, could vastly expand the potential of digital monies to support users beyond standard retail contexts.
\end{abstract}

Keywords: Mobile payment $\cdot$ China $\cdot$ money $\cdot$ qualitative study $\cdot$ special monies.

\section{$1 \quad$ Introduction}

Many digital and mobile payment systems have focused on fulfilling a small set of design needs, chiefly to increase transaction speed, and reduce cost of use [1-8]. But monies contain much more informal and nuanced uses (e.g., between friends, and with microenterprises [8]. These uses could alter the interactions the users would expect of digital monies), such as who should send the money, who the money is for, what the money is for, when the money should be sent, and on what condition the money should be sent. For example, if a group of co-workers is sharing a retirement gift for a colleague, these co-workers would need to split the cost evenly-not a 
straightforward interaction that we could easily perform with most digital monies. While research studies in HCI have pointed out design opportunities situated within these informal and nuanced mobile contexts [1-8], we have not yet understood how we can design digital monies to allow users to use monies more easily in these contexts.

In this paper, we address the research gap by identifying design principles guiding the design of digital monies so that they fit more readily into informal and nuanced mobile contexts. In order to identify these design principles, we conducted an exploratory study, examining the design of two successful digital payment apps, Alipay and WeChat Wallet, with specific attention to whether and how they serve nuanced activities. With the Chinese mobile payment market poised to hit nine trillion yuan (1.4 trillion USD) in 2016, these two mobile payment apps are currently dominating this market [9-11]. Numerous Chinese retailers, municipal services, peer-exchange services such as Didi Taxi (similar to Uber but used in China), and even instant messaging apps, are relying on these apps for payment. Thus, we ask the research question: What are the design principles of Alipay and WeChat Wallet that mediated the use of these apps to support nuanced practices?

We conducted 24 semi-structured formal interviews with mobile payment app users in Beijing, Hong Kong, and California. All these users were Chinese nationals. From March 27 to April 2, 2016, we also visited Beijing to conduct first-hand observations and additional informal interviews with mobile payment users such as restaurant owners and taxi drivers. Apart from examining the design of mobile payment apps supporting nuanced monetary activities, this case study is valuable to the $\mathrm{HCI}$ field in two other ways. First, while there were previous studies examining mobile payment technologies used in urban areas, most of this past research documented the ways in which entrenched retail payment practices (e.g., the use of credit cards) tend to stifle mobile payment innovations $[5,12]$. As far as we are aware, Alipay and WeChat Wallet are the first cases of mobile payment technologies being successfully introduced to a major urban city. These apps also fulfilled many previously unmet needs such as those of microenterprises and instant messaging users in the city.

Through grounded theory coding and analysis of our data, we identified the design principles of Alipay and WeChat that mediated the use of these apps to support nuanced practices. We arrived at the term special digital monies (special purpose monies), a term coined by the anthropologist Zelizer [13] which suggests that the attributes and meaning of a monetary transaction could change according to the specific social context. Presenting our findings through the special digital monies lens, we aim to highlight the ways in which designers need to identify the principles of designing digital monies for these special purposes. We have structured our paper by first discussing related work on special monies and design studies of mobile payment systems. We then introduce features of Alipay and WeChat Wallet to our readers. In the Findings section, we present five examples of special digital monies cases to illustrate how these mobile payment apps serve each specific activity. Finally, we provide concrete design implications for mobile tools supporting special digital monies activities. 


\section{Related Work}

In her paper, “The Social Meaning of Money: Special Monies," Viviana Zelizer [13, 14] discusses a social property of money - of changing meanings according to by whom and for what purposes it is being used. According to Zelizer [15]:

[W] hile the economic model assumes that all monies are the same in the modern world, the "special monies" model assumes that there is a plurality of different kinds of monies, each "special money" shaped by a particular set of cultural and social factors and is thus qualitatively distinct.

Zelizer [13, 14] used the concept special monies to challenge the more narrowly construed economic definitions of money, often taken for granted by institutions that assume the artifact can be universally defined using attributes of trades and exchanges $[13,16,17]$. Instead, Zelizer [13, 14] argues that users - in a myriad of social contexts - view and use money in vastly different ways beyond simple economic definitions (e.g., faster and cheaper). For example, Zelizer [13] examined "domestic money" in the early twentieth century, and analyzed the differences between "women's household money" and "husband's allowances." In her study, she found that "women's household money" was to be spent prudently, unlike the money of men. Household money were obtained from the husbands, who were at times unwilling and had to be coaxed to part with the money; and the money had to be used only for specific purposes [15]. Furthermore, in her analysis of manipulation and contest in "domestic money" within American households, she argues that gender role in this context changes the properties of money, including (1) "allocation"- - who gives who money and why, (2) "timing"-when the money is allocated, (3) "uses"-what the purposes of the allocated money are, and (4) "quantity"-how much money is allocated.

The concept of special monies can be useful to inform HCI researchers and designers to pay attention to how users see and use monies, which can be very different from the perspectives of considering money as homogeneous, neutral medium of exchange. This concept may be even more important as digital devices are offering new forms of payment options which may allow us to use money quite differently from the traditional cash and banking models [18]. Currently, research studies in HCI have already pointed out examples of how social practices could detract from a narrower set of digital payment design features, which commonly include transaction speed, and cost of use. Specifically, these features - transaction speed, and cost of use-have arisen from economic rationalization, an idea emerging from the work of Weber and Simmel [19]. And economic rationalization is already clearly seen in the design of monetary artifacts such as credit cards and credit ratings, which, while bringing some users certain convenience, also introduced uniformity to payment processes. The uniformity may sidestep nuanced ways in which users may like to use these monies [18, 19]. Olsen, at al. [8], who interviewed a variety of mobile payment users, argue that "evaluation criteria [for mobile payment] have to be expanded beyond 'functionality, completeness, consistency, accuracy, performance, reliability, usability, fit with the organization, and other relevant quality attributes' that are used within current design work."

One design feature often accompanying new designs of digital monies is that of increasing monetary transaction speed. Many studies have examined associated 
emerging technologies such as the contactless smart cards and credit cards [1-4]. For example, in the studies of stored value contactless smart-cards in congested cities, researchers focused on the ways these financial technologies offer crisp transactions for fast-moving urban dwellers [2, 3]. However, unexpected social situations may diminish the effectiveness of these monies. For example, Ferreira et al. [20] found that users' need for fast payment seems to become less prominent in less populated towns and cities [20]. And in an investigation of smart card uses in cities like London, Pritchard et al. [4] caution that these technologies introduced unexpected issues, such as diminishing social engagements between drivers and passengers, and suggest that designers consider social complexities of monetary uses more carefully.

The second design feature, seen in technologies such as the SMS-based payment platform M-Pesa, has been the lowering cost of using and setting up such systems in developing regions $[6,7]$. The argument is that these mobile payment systems allow users in developing regions with low-cost cell phones to send money home and to save money securely [6]. However, Gannamaneni et al. [5] have found that the same design features have had no success in the urban cities. For example, an SMS-based payment system introduced in Switzerland in 2005 offered the system free of charge to consumers, and charged the same costs as credit cards to businesses, but the system failed to take off [5].

Some studies have shown that money in different social contexts (e.g., different cultures) could be attached to different social meanings and used in different ways [8, $14,21]$. In the study of virtual currencies in Chinese online games, Wang and Mainwaring [21] have illustrated how these Chinese players have tended to use virtual currencies creatively to reinforce their social cohesion and group values [21]. These Chinese game players often generously share virtual gold and gaming accounts with their friends, a practice rarely observed among Western gamers [21]. However, these researchers have also yet to discuss general design implications which can be applied to support special money uses.

Importantly, Zelizer [13] argues that the ways money is being passed along from one user to another needs deeper examination:

No money, including market money, escapes such extraeconomic influences. For instance, at the turn of the century, not only the domestic dollar but other kinds of monies created different yet equally significant cultural and social dilemmas for American society. "Charitable money" raised questions about the proper uses and allocation of money as a gift among strangers or between kin, whether in the form of charity, wills, "ritual" gifts (for weddings, birthdays, bar mitzvahs, and Christmas), or even tippings, while "sacred money" provoked discussions about the moral quality of money... we must then explain the sources and patterns of variation among special monies, exploring how various structures of social relations and cultural values shape and constrain the qualitative life of different monies

If we consider the ways that different context may require users to transmit money differently from one person to another, then digital monies may also need to account for social rules governing how, when, to whom it is transmitted.

Lastly, to the best of our knowledge, there had not been any case of mobile payment technologies being successfully introduced to users in major urban cities. While previous studies borrowing economic design factors (e.g., speed, cost, or ease of use) 
have attributed this to emerging payment technologies encountering insurmountable challenges competing with entrenched technologies like the credit cards [5], the success of Alipay and WeChat Wallet directly raised the possibility that there may be design features of digital monies that could support a great variety of social situations among urban users. Thus, this study is poised to have significant impact on how HCI should conceptualize future modes of digital monies and payment systems, in order to serve the myriad ways which users have to deal with monies.

Thus, the main contribution of the study of Alipay and WeChat Wallet is that we will examine special purposes of digital monies within a selected sample of the Chinese context, and identify general design features of special digital monies.

\section{Background}

\subsection{Alipay}

Alipay is a third-party online payment platform launched by Alibaba Group on October 18, 2003 [22]. Initially, Alipay was designed as an online payment platform for Taobao (taobao.com), which is an online shopping website like Amazon and eBay. On May 26, 2011, Alipay obtained the first Payment Business Permit issued by the People's Bank of China, which allows its users to make payments to their friends, to mobile phone companies, prepaid cards, and municipal services [22]. By April, 2015, Alipay's mobile app had more than 270 million active users, who use it to make payments both online and in offline retail stores [23]. Today, more than 200,000 offline retail stores in China accept Alipay [22].

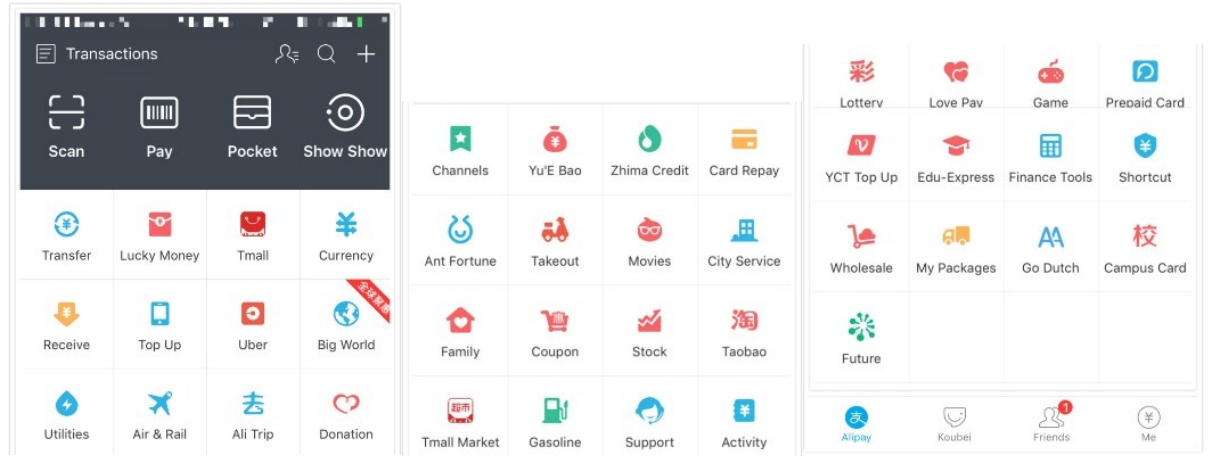

Fig. 1. The diagram shows the many money-related services provided by Alipay.

Alipay supports many money-related functions (see Fig. 1), such as money transfer between end users, quick pay though Quick Response Codes (QR codes), mobile top up, paying utilities, and in-app payment through third-party apps using Alipay SDK. For consumers, Alipay is free to use and does not charge a transaction fee. For most merchants, Alipay charges a fee of $0.6 \%$ per transaction. For merchants belonging to specific industries, such as gaming, computing, and lottery, Alipay charges a fee of 
$1.2 \%$ per transaction. Alipay allows both consumers and merchants to withdraw money from their Alipay accounts to designated bank accounts free of charge.

\subsection{WeChat Wallet}

WeChat is a mobile instant messaging app launched in 2011 by Tencent Group in China. As of December 2015, it was also the most popular IM in China, with more than 679 million monthly active users [24]. WeChat provides services similar to other IMs, such as voice chat, group chat, video call, location sharing, and message broadcast to multiple users at once; but beyond typical IM functions, the app also includes features seen on social networking sites (e.g., Facebook), such as status update, and online games.

In 2014, following Alipay's success in mobile payment, WeChat launched WeChat Wallet, a mobile payment system integrated into its IM platform. WeChat Wallet supports payment media similar to those of Alipay, including a "Quick Pay" feature via QR codes, and in-app payment through third-party apps using WeChat Wallet SDK. Like Alipay, WeChat Wallet has also included money-related services similar to those in Alipay, such as mobile phone bill and municipal service payments. As of the first quarter of 2015, WeChat Wallet had 400 million users [25].

Like Alipay, WeChat Wallet charges no fee for consumers to transfer money to anyone. But for most merchants, WeChat Wallet charges a fee of $0.60 \%$ per transaction (same as Alipay), except for merchants of specific industries like online gaming, which pay up to $2 \%$ fee per transaction [26].

WeChat Wallet used to charge no withdrawal fees, like Alipay; but since March 1, 2016, Tencent modified its terms of use, and only allows users (both consumers and merchants) to freely transfer money from their WeChat Wallet to a designated bank up to a cumulative amount of 1,000 yuan, beyond which the users will have to pay a $0.1 \%$ withdrawal fee (with a minimum fee of 10 cents).

\section{$4 \quad$ Method}

Between February 22 and May 5, 2016, we conducted 24 in-depth and semistructured formal interviews with Alipay and WeChat Wallet users, of which 16 were residents of Beijing, five of Hong Kong, and three of California. We first conducted five interviews in Hong Kong as a preliminary step to understand Alipay and WeChat uses and commonly used features. These interviews were conducted in person. We recruited these participants from a one-year media art postgraduate program. They were citizens of mainland China, and were frequent users of Alipay and WeChat Wallet.

From March 27 to April 2, 2016, we visited Beijing, where we conducted 16 additional interviews with local users. Our second author is a Chinese living in California who has been using Alipay and WeChat Wallet frequently. First, our second author recruited three friends and residents in Beijing to be our initial interviewees. Second, we snowballed this sample and eventually found another 13 interviewees. Although we used the snowball sampling method, we paid special attention to diversifying our interviewees in terms of their occupation, educational background, and gender. 
Among these 16 interviews in Beijing, 14 were conducted in person, and two were conducted on the phone. In order to examine possible variation in practices by overseas Chinese (e.g., expatriates and foreign students), our second author further recruited three friends who were residents of California. We intentionally snowballed our samples to the US because through the course of our interviews, we realized that when senders and receivers live in different locations, they could conceive alternative ways to use these apps, which may not otherwise manifest when they live in the same country and could meet more readily.

Among the 24 participants, 15 were females and 9 were males. Their ages ranged from 20 to 33 years old; 13 were postgraduate students, two were undergraduate students, and nine were working adults. All of our participants in Beijing and California were regular users of both Alipay and WeChat Wallet apps. The purpose of our study was not to identify an exhaustive list of practices around the two apps (which is impossible for a study consisting only 24 participants), but to uncover sufficient variations in order to identify useful design principles. We asked our participants questions including reasons for using these apps, and how they had used them as they were conducting activities with their friends, family members, and colleagues. This approach follows the qualitative user research tradition of asking users descriptive questions, thus probing their day-to-day practices around the two apps, in order to for us to gather the data which we analyzed to uncover meanings and design implications [2730]. All interviews were audio-recorded and transcribed. We retained original orthography and punctuation in interview quotes. We use pseudonyms to anonymize and protect our participants' identity.

While we were in Beijing, we also conducted participant observation and informal interviews in person with merchants such as taxi drivers, food peddlers, and restaurant owners regarding their experience with Alipay and WeChat Wallet. We took photos of Alipay and WeChat Wallet being used by these merchants.

We performed memoing and theoretical sampling during and after each interview [31] from the time we started our interviews in Hong Kong. We paid attention to how features of these two apps served the Chinese users in different social contexts. For example, we identified early on in Hong Kong that while there were common uses of Alipay and WeChat for online shopping across a large section of the user population, those who live in mainland China may have other uses such as paying bills. Thus, we realized the importance of interviewing users who live in mainland China. While in Beijing, we were informed by student interviewees of other forms of gifting and play practices among office workers and distant friends, and we thus interviewed office users and Chinese who reside in the US. We utilized the grounded-theory method of axial coding [31] to identify how these mobile app features integrated into various social settings, social norms, and hidden rules inhabiting these contexts. First, we identified several activities mediated by different uses of the apps. Second, in each of these activities, we identified the ways in which different actors and contexts change meanings and interactions with the apps. Third, we identified how the apps' designs allow these users to choose how the payment apps behave and interact with them in order to fit into these different activities. Finally, our analysis led us to identifying theories and concepts to explain how these apps were supporting informal and nuanced mobile payment activities, and arrived at special monies and special digital 
monies as our theoretical frame, as well as the codes presented in the Findings and Discussion sections.

\section{$5 \quad$ Findings}

Alipay and WeChat Wallet have facilitated use of digital monies in new mobile payment contexts in China, which contributed to our participants using them frequently. Note that the concept of special monies does not assume that money used in commerce is "ordinary." In fact, Zelizer [13] wrote that "Market money does not escape extraeconomic influences but is in fact one type of special money" (p. 351). That is, even in market contexts, there are social and cultural nuances influencing money use (e.g., [13]). Our Findings section reflects this idea by including "mobile and placeless money" as a special money context-which serves to highlight special monies' transcending definition. In our coding, we identified five examples including "mobile and placeless money," "ceremonial money," "play money," "dining money," and "gift money." These are only a subset of what may encompass special digital monies, particularly in a country as diverse and populous as China; but these activities illustrate how digital monies uses vary in attributes and design needs in a myriad of contexts, which helps set up the stage for our later discussion on design implications.

\subsection{Providing Interfaces for "Mobile and Placeless Money"}

We use the phrase "mobile and placeless" to refer to actors' monetary activities which are on the move, or for other reasons, disconnected from retail infrastructure. For example, retailers in malls have access to telephone lines and sales counters to install standard point-of-sales systems. However, mobile and placeless microenterprises, such as taxi drivers in China, often do not have this luxury or the resources to install the equipment.

Alipay and WeChat Wallet facilitated the digitization of "mobile and placeless money" by bringing in sole proprietors and students, whose monetary activities had previously mostly comprised cash transactions.

One way in which Alipay and WeChat Wallet ease the way Chinese taxi drivers receive digital payments from customers is through printed QR codes (see Fig. 2), which facilitate payments in mobile contexts.

Fig. 2 shows how a Chinese taxi driver was able to neatly tuck away the card in a card slot in his taxi. In Beijing, every taxi driver we met (more than 10 of them) had accepted both Alipay and WeChat Wallet as payment options; but they preferred Alipay as it did not charge any withdrawal fee.

These printed and self-service QR codes also worked for sole proprietors receiving payments in amounts too small or too frequent to be feasible for credit card transactions. For example, we had seen food peddlers accepting Alipay and WeChat Wallet payment through printed QR codes, prominently displayed at their stall front, to avoid handling loose change with their hands. One participant-Yunqing, an undergraduate student from Beijing - had used Alipay for small purchases throughout the campus. She said: 
There are many food stalls and peddlers in the campus, selling pancakes and street food. And they have supported Alipay. Now, for example, for one or two yuan [worth of goods], it is troublesome for them to receive your money, or to return you any change. But Alipay is convenient.

Without using their hands to handle money, these peddlers could focus on food preparation, which eased their work processes. These sole proprietors and their customers had saved a lot of effort and time by conducting their exchanges in more efficient ways.
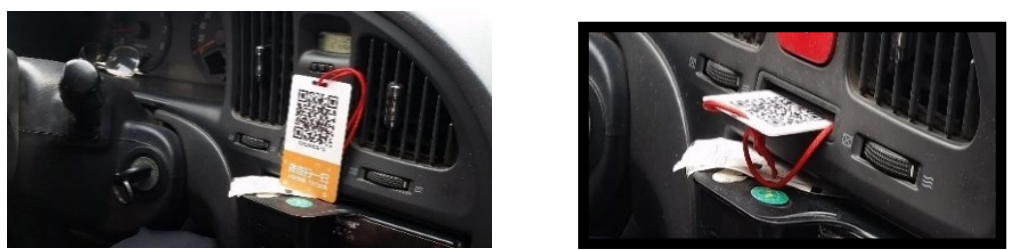

Fig. 2. A WeChat Wallet QR code card (left), tidily tucked away in a card slot when not in use (right), was used by a taxi driver to collect customer's payment.

Another example of "mobile and placeless money" comes from that of ad-hoc labor required by Peking University's student clubs, associations, and student projects. Within the university, many student associations and research groups regularly distribute survey questionnaires to Peking's student population. And it was becoming commonplace that the token reimbursements to respondents were paid through WeChat Wallet to their IM accounts. For example, Keli, another undergraduate student from Beijing, told us:

Many students need to distribute questionnaires, like you [are conducting this interview]. They have certain requests or some tasks [for the respondents], but each questionnaire will take one or five minutes. And there is no way to know if the respondent filled in the questionnaire. If they did, they are helping you, but you will never know. But if you [send the questionnaire] along with a payment [in WeChat], you will make the respondent feels like he owes you a favor, and he will become more inclined to fill in the questionnaire.

This way, students conducting voluntary work have used digital payments to tokenize favors (i.e., digital money as a request for help) in order to encourage participation.

In these cases, sole proprietors and students benefitted from ubiquitous mobile payment options presented as QR codes displayed in physical forms (see Fig. 2), or through IMs (e.g., for student activities). These payment options met "mobile and placeless money" needs in three ways: (1) the QR Code cards can be installed in convenient locations in taxis and peddler carts; (2) the merchants do not have to receive payments with their hands, thus smoothing work processes for these microenterprises; and (3) workers without access to retail infrastructure (e.g., students) can use digital payment options. 


\subsection{Bringing Hongbao "Ceremonial Money" to Digital Spaces}

A cultural artifact in China, known as hongbao (literally "red envelope" or "red packet"), has deep significance as a mediator of relationships between family members, friends, and colleagues. A hongbao, containing a token sum of money, can be given by one Chinese to another for many reasons, including childbirth, Chinese New Year, marriage, birthday, promotion, and other ceremonial occasions.

Both Alipay and WeChat Wallet digitized hongbao within their payment apps (see Fig. 3), thus bringing the use of "ceremonial money" to online and digital spaces.

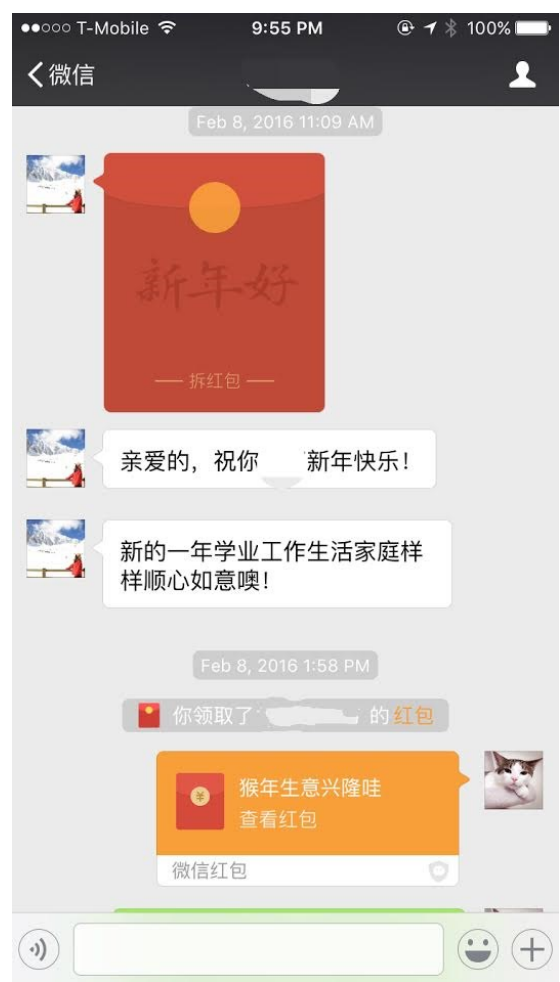

Fig. 3. A Happy Chinese New Year Hongbao in the WeChat conversation.

In modern-day China, hongbao giving is increasingly difficult for young Chinese who had left their hometowns to work in the cities. This changing social structure of family members needing to maintain traditional ties across distance diminishes the effectiveness of paper hongbao. For this reason, the giving of digital hongbao is becoming popular among distant relatives. For example, Meilin, a writer and journalist, who lives about 500 miles away from her hometown, explained:

We always send hongbao [back home] during festivals. For example, during [the last] Chinese New Year, I sent a hongbao to my niece (through WeChat Wallet). We could not meet since we live in in different cities. If we could meet face to face, I would rather give her traditional [paper] hongbao instead. 
The giving of digital hongbao embodies lower cultural value when compared with traditional paper hongbao, but its digital forms are acceptable when the giver and recipient cannot meet in person.

As seen in Fig. 3, a digital hongbao imitates a physical hongbao in appearance (a red envelope), while also allowing users to send text messages along with it. In mainland China, it is customary for hongbao givers to write congratulatory or auspicious messages on the physical hongbao. This digital hongbao feature meets Chinese "ceremonial money" needs by allowing users to express cultural meanings through a digitized monetary artifact. In other words, users can send symbols of love and blessing — with money - to their family members.

\subsection{Reorganizing Digital Money Flow as a Form of "Play Money"}

The WeChat IM allows large number of users to create a dedicated chat room known as a WeChat Group. In a WeChat Group, users can exchange one form of digital hongbao, known as a Lucky Hongbao (拼手气红包). First, a user can contribute a Lucky Hongbao containing a certain amount of money to the chat group; she then specifies the number of times this hongbao can be drawn on. Members of the group then take turns to draw on the hongbao, and each draw will recover a random, nonaverage, amount of money (known as Lucky Money); everyone within the group can see how much Lucky Money other members have drawn; this continues until the hongbao has been drawn for the indicated number of times, at which point the hongbao will be fully spent. The one who drew the highest amount of Lucky Hongbao will be assigned a crown badge representing Luckiest Draw (see Fig. 4).

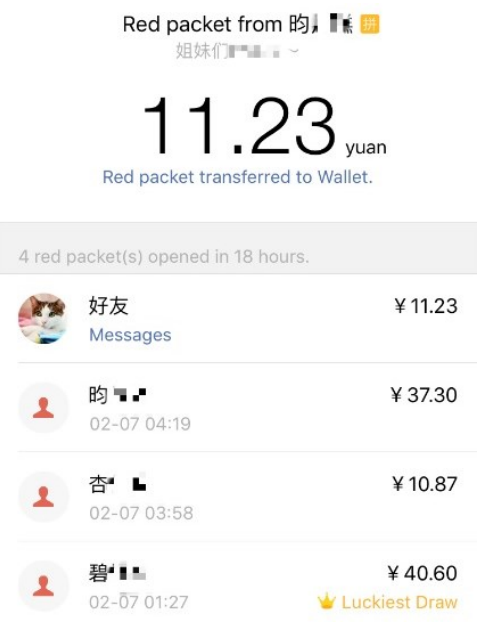

Fig. 4. A list of Lucky Money gained by people within a WeChat Group from a Lucky Hongbao. The list shows who had the Luckiest Draw.

Through this reorganization of money flow - by making receiving amounts randomLucky Hongbao created a form of "play money" within the instant messaging environment. 
Lucky Hongbao carries the quality of playfulness when small quantities are gifted to friends. According to our participants, playing with Lucky Hongbao is a good way to kill time and promote bonding among family members, friends, and colleagues. For instance, Xiaoyu, a master's student in Beijing, told us:

We treated this as a game. Let's say someone contributed a hongbao, and see who may draw the largest amount, say I divide the hongbao into 10 piles. Whoever gets the largest amount will contribute the next hongbao. This is how we played. But this is just for fun, you cannot earn or lose much out of it. But it helps killing boredom, and we can play with it together.

According to Xiaoyu, this person who won the Luckiest Draw will also become the next player to contribute a Lucky Hongbao. In this game, digital hongbao becomes a gaming artifact to spice up social relations (聯絡感情). Another participant described such games as not so much containing notions of gifting, as the amount involved is usually small (e.g., 50 yuan), but more akin to “sharing snacks" in offices (分享零食).

Interestingly, senior management in Chinese organizations and workplaces are also beginning to use Lucky Hongbao as an alternative to digital hongbao, shifting traditional gifting practices in these places. When senior staff gives traditional paper hongbao to junior staff, the act contains connotations of goodwill and gratitude for the staff's services. Traditionally, this gifting practice happens during Chinese New Year, and other celebrative occasions. Staff will usually receive a certain amount of money but sealed in a red packet, so that no one will know how much the other person has received. But today, in some offices, especially those in which colleagues have set up a WeChat Group, managers have at times opted to give Lucky Hongbao to their subordinates instead - to add an element of fun and loosen the rigidity of traditional hongbao practice. When the amount each person receives is different and visible to everyone, this activity gives rise to a new play activity, which we translate as “Hongbao Rush" (搶红包), a light-hearted contest among employees to see who can draw the largest hongbao. Qinzi, an editor who works in a publishing company, explained:

There are also WeChat Groups for my company. Our superiors give us physical hongbao during Chinese New Year. Each group has about 20 to 30 people. This hongbao is meant to add fun into the [office] atmosphere... with WeChat Wallet, they also give us more frequently [but each time] in smaller amounts for fun.

For Qinzi and her colleagues, with the giving of Lucky Hongbao being so easy and casual, her superiors can perform this gifting practice more often and casually, thus altering its ceremonial meanings.

In this context, Lucky Hongbao meets "play money" needs by reorganizing money flow from a standard "one person to one person format," into a "one to many format, but with a condition that each person will receive a random amount." As in previous cases, while the economic value of the hongbao money remains the same, these design attributes change the connotation of hongbao giving to include a playful tone. 


\subsection{Deciding Who Pays the "Dining Money"}

In China, it is commonplace for family members, friends, and colleagues to pay for purchases and meals of their counterparts. For example, a colleague could offer to pay for a meal, or a family member could pay for the purchases of loved ones (similar to gift registry practice, in which the form of gift is determined by the recipient). And Chinese users have used Alipay and WeChat Wallet to support "dining money" practices, by intentionally blocking or altering transactions between payers and payees to determine who will foot the bill in the particular dining contexts.

In the Chinese dining tradition, it is often considered impolite for a group of diners to even contemplate the idea of splitting bills, or "go dutch." Someone, by social norms, has to offer to pay for everyone else, and this person is usually a hierarchically senior person. For example, Linhui, a master's student in Beijing, told us:

[Splitting bills] hurts our relationship. If it becomes too much [for someone to pay all the time], I will pay this time, and you will pay next time... but we will never split the bill in half. Splitting bills is very weird in our culture.

However, in modern China, friends and colleagues dine together very often, and the practice of paying for someone else has thus become less meaningful - even unfair if someone has been paying too often for others. With the use of Alipay, users have found a way to sidestep this unfairness; because while the splitting of the bill in a restaurant is still considered socially and culturally awkward, the repaying of a bill on the digital platform is not, as Xiangdong, another master's student, explained:

If someone [fights] to foot the [dining] bill, and we [feel it is] unfair to him, the rest of us will transfer our share of the bill to him. Due to Alipay's design, he cannot reject our transaction to him on Alipay.

Alipay does not allow the payee to refuse payment, therefore relieving the payer of any guilt over not making an effort to pay for others. This approach of splitting dining bills, however, is not available on WeChat, which allows the payee to refuse a payment. Therefore, our participants have tended to prefer Alipay to WeChat Wallet for sharing dining expenses.

In this context, Alipay met "dining money" needs by allowing payers to turn down repayment, thus halting the flow of money to manage complex practices of "dining money."

\subsection{Getting Someone to Pay "Gift Money"}

Lastly, Alipay and WeChat Wallet have made it possible for good friends and loved ones to pay for each other's purchases - with a symbolic meaning of "gift money"even when they are a distance apart. Both Alipay and Wechat Wallet include a Get Someone To Pay feature (see Fig. 5). After a user is done shopping, he can indicate a payer within his friends list and send out a Get Someone to Pay request. For instance, Yuxin, a PhD student who lived in California, told us:

Last year, I went back to China for several days. However, one of my best friends could not meet me as she was traveling. She wanted to express her love to me. Thus, she asked me to place a coffee order online at a Coffee Shop and send out a 
"get someone to pay" request to her on Alipay. In this way, she instantly bought a cup of coffee for me, although she was hundreds of kilometers away. I was so touched.

This feature makes it easier for our informants to show concerns for friends and families whom they do not see often.

In this context, the Get Someone to Pay feature met "gift money" needs by allowing buyers to direct the payment to a third person, altering the flow of money so as to symbolize a form of cultural expression in gifting practices.

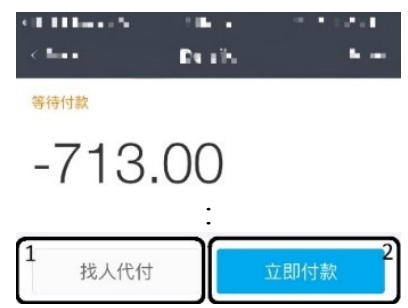

Fig. 5. "Get Someone to Pay" feature on Alipay (1. Get Someone to Pay; 2. Pay Instantly)

Alipay and WeChat Wallet have served our participants in many special monies activities - from everyday commuting to dining, shopping, and socializing. They served not only economic purposes, but were also integrated into contexts of "mobile and placeless money," "ceremonial money," "play money," "dining money," and "gift money." To the extent that these covered significant aspects of daily uses, Alipay and WeChat Wallet are thus becoming ubiquitous in large cities like Beijing. In fact, many of our informants, having used these apps so much, reported the experience of not even aware if they carried any cash at all in their physical wallets. For instance, when we asked one participant how much cash he had in his wallet. he pondered for a moment, then picked up his wallet, looked into it, and drew from it the only 100 yuan note he had. He paused to think where it came from, and quickly recalled that one of his colleagues had repaid him for an earlier purchase. "I don't know why he paid me in cash," he candidly said; "Alipay would have been better."

\section{Discussion}

We have reported the ways in which Alipay and WeChat Wallet are remarkable in their ability to support mobile and nuanced monetary activities, and for our informants to nearly eliminate traditional cash payments on a day-to-day basis. Our informants have used these apps to utilize money for microenterprises and student activities, maintaining family relationships, facilitating play, and supporting dining and gifting protocols. In order to support these activities, the apps have provided features which alter transactional processes, such as to graphically depict money as a hongbao gift, or as a gaming token (i.e., in Lucky Money). Based on this data, we identified special monies as our lens to emphasize our need to design digital money by benchmarking it against purposes beyond that of straightforward retail exchanges (i.e., faster and cheaper transactions with money flowing from consumer to merchant) $[2,3,32,33]$, 
and to pay attention to situated actions which influence the flow, timing, rules, and participants of monetary uses. And special digital monies can be considered new forms of special monies for digital artifacts - much more malleable and appropriable than cash money as originally examined by Zelizer (e.g., sending digital monies in virtual contexts like an IM chatroom). For example, while the Chinese food peddlers had to handle paper money in the past, they can rely on QR codes to receive these payments today. Therefore, special digital monies have additional potential to improve traditional special monies activities.

We analyzed our findings to uncover general design principles which can support special monies activities, and we identified two principles: (1) a multimodal on-screen representation of money and its different uses to befit varying meanings of payment in digital spaces (e.g., within an IM), and (2) a physical and customizable payment media design that can be embedded on user-defined real world artifacts. We will discuss these two principles in this section, and end our discussion by addressing additional concerns about designing for special digital monies.

\subsection{Multimodal UI On-screen Representations to Support Varying Meanings of Payment in Digital Spaces}

Alipay and WeChat Wallet provide users with flexible and multimodal on-screen representations of money and its possible behaviors; that is, money is fittingly represented as a direct digital payment, digital hongbao, Lucky Hongbao, and Get Someone to Pay. These multimodal on-screen designs allow users to use money in appropriate ways to express specific cultural connotations - even to create new meanings (e.g., in "play money" in an office) - beyond treating money as utilitarian instruments for impersonal exchanges.

Applications supporting special monies activities have to afford sufficient flexibility so that users can select appropriate money behaviors befitting a specific context. For example, when digital money is represented on-screen as a Lucky Hongbao within lines of an online discourse, it changes that discourse with additional meanings of luck, fun, and excitement. Our study of Alipay and WeChat Wallet shows that through design of on-screen payment media which are adaptable, digital money could even create new values by enabling new forms of social interactions within these exchanges. In the Chinese cultural context, money can take the form of an economic exchange medium, a gift, an expression of goodwill or gratitude, or an embodiment of blessing. For instance, money, in the Chinese forms of hongbao, is a mediator of social relationships at home, with friends, or in offices. But at other times (e.g., as payment to survey respondents), money may yet demand its economic qualities as an efficient medium of exchange. These varying meanings could be represented onscreen - as a favor for survey respondents, a gift for loved ones, gaming artifacts to kill time, or a forceful but culturally admissible mode of repaying dining bills.

In order to assist designers to consider ways in which software could support digital monies, we provide the following set of transactional attributes derived from our findings:

1. Actors: Who are the payers, and who are the payees? There can be multiple payers and payees in a transaction. 
2. Context: Where is this transaction going to take place? For example, within instant messaging, online forums, a mobile app, or other digital spaces.

3. Representation: How should money be graphically represented? For example, money can be represented as numbers on screen, or as graphical representations of digital artifacts, such as hongbao.

4. Quantity: How much money will each payer give, and each payee receive?

5. Flow: How will the money flow from one actor to another? The money may flow from one actor to another, one to many, many to one, many to many, or in a combination of these processes. Certain money flow may also be forbidden.

6. Timing: When and under what conditions will the above transaction rules be activated? For example, Lucky Money is spent when it has been drawn the defined number of times.

Compared with Zelizer's original analysis of how gender role and context influence "timing," "allocation," "uses," and "quantity" of cash money [13], our transactional attributes are more focused on technical features and new potentials of a digital payment system. We contributed "representation" to reflect how digital devices can change how digital monies look on a user interface, unlike traditional forms of cash currencies. In Zelizer's [13] study, her notion of "allocation" implies that a housewife could obtain money as her regular allowance, or she could ask for it from her husband; and the notion of "uses" suggests limited purposes for which she could spend the money (e.g., to buy her children clothes). Our attribute "flow," which focuses on the division of money and possibility of complex movements between multiple senders and receivers, combines both Zelizer's notions of "allocation" and "uses" [13]. By having the freedom to choose between different "flow" of money, users can fulfill both digital money "allocation" and "uses" at the same time.

In the following, we further elaborate how these transactional attributes were derived from our Findings, and how they can be used. We picked "Mobile and Placeless Money" and "Play Money" as examples because they are different in most attributes. And we listed each specific design feature right next to each attribute in Table 1.

Table 1. Identifying transactional attributes from the examples of "Mobile and Placeless Money" and "Play Money" (continued)

\begin{tabular}{|l|l|l|}
\hline \multicolumn{2}{|c|}{ Mobile and Placeless Money } \\
\hline $\begin{array}{l}\text { Transactional } \\
\text { attributes }\end{array}$ & Usability issues & Design features \\
\hline Actors: Microenterprise and consumer & No access to credit card terminals & $\begin{array}{l}\text { The QR Code cards can be installed } \\
\text { in convenient locations in taxis and } \\
\text { peddler carts; workers without ac- } \\
\text { cess to retail infrastructure (e.g., } \\
\text { students) can use digital payment } \\
\text { options }\end{array}$ \\
\hline Representation & $\begin{array}{l}\text { Some merchants find it cumber- } \\
\text { some to handle cash or receive }\end{array}$ & $\begin{array}{l}\text { Consumers can pay directly to QR } \\
\text { codes, thus smoothing work pro- }\end{array}$ \\
\hline
\end{tabular}




\begin{tabular}{|c|c|c|}
\hline & payment on mobile phone & cesses for these microenterprises \\
\hline Quantity & $\begin{array}{l}\text { Small quantity of money in each } \\
\text { transaction }\end{array}$ & Low transaction fee \\
\hline \multicolumn{3}{|c|}{ Play Money } \\
\hline $\begin{array}{l}\text { Transactional } \\
\text { attributes }\end{array}$ & Usability Issues & Design feature \\
\hline \multicolumn{3}{|c|}{ Actors: Family members / friends / colleagues } \\
\hline Context & $\begin{array}{l}\text { The Lucky Hongbao game is } \\
\text { played in a chatroom }\end{array}$ & $\begin{array}{l}\text { WeChat supported money transac- } \\
\text { tions in the chatroom interface }\end{array}$ \\
\hline Representation & $\begin{array}{l}\text { The tone of payment is fun and } \\
\text { play }\end{array}$ & $\begin{array}{l}\text { WeChat Wallet supported Lucky } \\
\text { Hongbao through fun representa- } \\
\text { tions (e.g., crown badge) }\end{array}$ \\
\hline Quantity & $\begin{array}{l}\text { Small quantity of money in each } \\
\text { transaction }\end{array}$ & Low transaction fee \\
\hline Flow & $\begin{array}{l}\text { The game requires money to flow } \\
\text { in a one player to many players } \\
\text { format; each receiver will receive } \\
\text { random and non-average amount }\end{array}$ & $\begin{array}{l}\text { WeChat allows the sender to specify } \\
\text { the number of times a pool of mon- } \\
\text { ey can be drawn on; each draw will } \\
\text { allocate a random amount from the } \\
\text { pool to be sent }\end{array}$ \\
\hline Timing & $\begin{array}{l}\text { Each receiver determines when } \\
\text { she wants to draw from the pool } \\
\text { of money. }\end{array}$ & $\begin{array}{l}\text { Each receiver initiates the draw } \\
\text { herself }\end{array}$ \\
\hline
\end{tabular}

From these two examples in Table 1, each of these attributes can be altered to conform to intended meaning of money in a particular payment context. For example, the Get Someone to Pay feature adds a third-party payee (who is not the consumer or the merchant) into the transaction, and adds a form of "gift money" connotation into that purchase.

\subsection{Customizable Media Designs to Embed on Physical Artifacts}

Alipay and WeChat Wallet provide a physical and customizable payment mediumthe QR codes - which can be printed out, enlarged, and be displayed on cards, tables, storefront, and any other convenient physical artifacts so as to blend into the physical exchange context.

Despite money today being pervasively transacted in digital forms, we still saw contexts relying on physical monetary artifacts to support transactions, and these contexts (in our study) typically happened with mobile and microenterprises. On the other hand, physical spaces seem to have more limited uses for family and friends, who are more likely to transact over digital spaces. In these physical spaces, merchants have chosen to display the payment medium on artifacts most convenient to them and their customers.

Taking food peddlers as an example, their hands are too busy and it would be considered unhygienic to handle smartphone apps. Since their customers often clutter prominently in front of their stall, a large printed QR code can be appropriately dis- 
played in front of their crowded stall for these customers to see. Since the payment medium is detached from the mobile app, other sole proprietors can display them on any physical artifacts suited to their environments.

We also took note of QR code uses within peer-exchange economies in China [34] An example of such economies includes the peer-exchange car sharing network Didi Taxi. In the US, while companies offering money-mediated peer exchanges tend to build digital payments into their apps [35], many peer-exchange service apps in China have opted for QR codes and other payment interfaces offered by Alipay and WeChat Wallet. Thus, the relationship between mobile payment technologies and smartphone based peer-exchange economies should be examined more closely.

Importantly, the customizable payment media features in these Chinese mobile payment apps are simple yet novel to HCI. To our knowledge, most mobile payment designs had offered a fixed on-screen or physical payment medium without variability - for example, contactless smartcards, SMS, or a standard payment gateway $[3,7$, 21]. Similarly, Google has offered payment through Gmail, while Facebook offers payment through its IM Messenger; but even these offer no alternative options. Also, new classes of financial technologies such as the Apple Pay are even restrictive in their uses to specific smartphone models. This is interesting since end-user customization and appropriation, a staple topic in HCI [36-38], appears to have not yet informed the design of digital money. We question the need to rigidly couple payment platforms and media designs, which seems counterintuitive to the adaptive potentials of software artifacts. In this sense, one of the strengths of the design of Alipay and WeChat Wallet is providing a range of transactional media and features which allow users to mix and match themselves; and through user appropriation, users become the agent which makes the money "special."

\section{Conclusion}

Special monies are changing meanings of money according to the social contexts in which they are being used [13]. In this study, we examined how two mobile payment apps, Alipay and WeChat Wallet, serve special digital monies activities of Chinese residing in Beijing, Hong Kong, and California. Through our interviews with participants, as well as fieldwork in Beijing, we found that Alipay and WeChat Wallet are successfully used in many nuanced transactional contexts due to their multimodal and customizable payment media designs. In terms of multimodal design, the designers have created several different on-screen representations of money which can be used flexibly to support Chinese monetary activities online. Thus, we argue that designers could support other forms of special digital monies by providing payment media designs which users could easily customize and appropriate for myriad intents and purposes. 


\section{Acknowledgements}

We thank the participants of this research. We also thank the reviewers for their suggestions to improve the paper. The work described in this paper was partially supported by grants from City University of Hong Kong (Project No. 6000535).

\section{References}

1. Kaye JJ, Mccuistion M, Gulotta R, Shamma D a (2014) Money Talks: Tracking Personal Finances. Proc 32nd Annu ACM Conf Hum factors Comput Syst - CHI '14 521-530. doi: 10.1145/2556288.2556975

2. Chau PYK, Poon S (2003) Octopus: an e-cash payment system success story. Commun ACM 46:129. doi: 10.1145/903893.903927

3. Mainwaring SD, March W, Maurer B (2008) From meiwaku to tokushita! Lessons for digital money design from Japan. Proc SIGCHI Conf Hum Factors Comput Syst 21-24. doi: 10.1145/1357054.1357058

4. Pritchard G, Vines J, Olivier P (2015) Your Money's No Good Here: The Elimination of Cash Payment on London Buses. In: Proc. 33rd Annu. ACM Conf. Hum. Factors Comput. Syst. - CHI '15. ACM Press, New York, New York, USA, pp 907-916

5. Gannamaneni A, Ondrus J, Lyytinen K (2015) A Post-failure Analysis of Mobile Payment Platforms. In: 2015 48th Hawaii Int. Conf. Syst. Sci. IEEE, pp 1159-1168

6. Kuriyan R, Nafus D, Mainwaring S (2012) Consumption, Technology, and Development: The "Poor" as "Consumer." Inf Technol Int Dev 8:1-12.

7. Wyche SP, Oreglia E, Ames MG, et al (2012) Learning from marginalized users: reciprocity in HCI4D. In: Proc. ACM 2012 Conf. Comput. Support. Coop. Work Companion - CSCW '12. ACM Press, New York, New York, USA, p 27

8. Olsen M, Hedman J, Vatrapu R (2012) Designing digital payment artifacts. Proc 14th Annu Int Conf Electron Commer 161-168. doi: $10.1145 / 2346536.2346568$

9. FinTech Asia (2015) Alipay vs WeChat: War of Chinese Payments. FinTech Asia

10. Mobile Ecosystem Forum (2016) China market focus: mobile payments. Mob. Ecosyst. Forum

11. Don Weinland (2016) Can the state take China's mobile payments market in 2016? Experts think not. South China Morning Post

12. Evans DS, Schmalensee R (2004) Paying with plastic: The digital revolution in buying and borrowing. The MIT Press, Cambridge, MA

13. Zelizer VA (1989) The Social Meaning of Money: "Special Monies." Am J Sociol 95:342-377.

14. Zelizer VA (1999) How do we know whether a monetary transaction is a gift, an entitlement, or compensation? In: Ben-Ner A, Putterman L (eds) Econ. Values, Organ. Cambridge University Press, pp 329-333

15. Zelizer V a (2011) Economic Lives: How Culture Shapes the Economy. Econ Lives How Cult Shapes Econ 1-478. doi: 10.2307/j.ctt7rgdv 
16. Marx K (1992) Early Writings. Penguin

17. Simmel G (2011) The Philosophy of Money. Routledge

18. Rogoff KS (2016) The Curse of Cash. Princeton University Press, Princeton

19. Ritzer G (1995) Expressing America: A Critique of the Global Credit Card Society. SAGE Publications, Thousand Oaks, CA

20. Ferreira J, Perry M, Subramanian S (2015) Spending Time with Money: From Shared Values to Social Connectivity. In: Proc. 18th ACM Conf. Comput. Support. Coop. Work Soc. Comput. - CSCW '15. ACM Press, New York, New York, USA, pp 1222-1234

21. Wang Y, Mainwaring SD (2008) Human-Currency Interaction: learning from virtual currency use in China. In: Proc. ACM CHI 2008 Conf. Hum. Factors Comput. Syst. pp 25-28

22. Alipay (2014) About Alipay. In: alipay.com. https://ab.alipay.com/i/jieshao.htm. Accessed 29 Apr 2017

23. Sina Technology (2015) Alipay has surpassed 270 million active users, exceeded $80 \%$ of mobile payment market 支付宝钱包活跃用户数 2.7 亿移 动支付份额超 $80 \%$. tech.sina.com.cn

24. TechWeb (2016) Wechat surpassed 700million users; Tencent: Fees will be charged for Wechat Wallet withdrawal 微信用户已达7亿 腾讯: 零钱提现 必须收费. techweb.com

25. Sohu (2016) New data: WeChat has 549 million monthly active users, and WeChat Wallet has 400 million users! 微信最新数据: 月活跃5. 49亿, 支付 用户达 4 亿! sohu.com

26. Tencent Customer Service (2017) Rates and settlement cycles for different kinds of merchants 商户类目对应资质、费率、结算周期. In: kf.qq.com. https://kf.qq.com/faq/140225MveaUz1501077rEfqI.html. Accessed 29 Apr 2017

27. Spradley JP (1988) Ethnographic Interview. Harcourt Brace Jovanovich, San Diego, CA

28. Fine GA (1993) Ten lies of ethnography: Moral dilemmas of field research. J Contemp Ethnogr 22:267-294. doi: 10.1177/089124193022003001

29. Geertz C (2005) Deep play: notes on the Balinese cockfight. Daedalus 134:56-86. doi: 10.1162/001152605774431563

30. Grudin J, Grinter RE (1994) Ethnography and design. Comput Support Coop Work 3:55-59. doi: 10.1007/BF01305846

31. Strauss AL, Corbin JM, Strauss AL (2014) Basics of Qualitative Research. SAGE Publications, Thousand Oaks, California

32. Weisner S (2012) Quantum Money. Commun ACM 55:84-92. doi: $10.1145 / 2240236.2240258$

33. Panurach P (1996) Money in electronic commerce: digital cash, electronic fund transfer, and Ecash. Commun ACM 39:45-50. doi: $10.1145 / 228503.228512$

34. Carroll JM, Bellotti V (2015) Creating Value Together: The Emerging Design Space of Peer-to-Peer Currency and Exchange. Proc ACM 2015 Conf Comput Support Coop Work Soc Comput CSCW '15. doi: $10.1145 / 2675133.2675270$ 
35. Ikkala T, Lampinen A (2014) Monetizing Network Hospitality: Hospitality and Sociability in the Context of Airbnb. Proc ACM 2014 Conf Comput Support Coop Work - CSCW'14. doi: 10.1145/2675133.2675274

36. Nardi BA (1993) A Small Matter of Programming: Perspectives on End User Computing. SIGCHI Bull. doi: 10.1145/191642.1047947

37. Dourish P (2003) The appropriation of interactive technologies: Some lessons from placeless documents. Comput Support Coop Work CSCW An Int J 12:465-490. doi: 10.1023/A:1026149119426

38. March W, Jacobs M, Salvador T (2005) Designing technology for community appropriation. In: Proc. SIGCHI Conf. Hum. Factors Comput. Syst. - CHI'05. pp 2126-2127 